\title{
A system-theory-based model for monthly river runoff forecasting: model calibration and optimization
}

\author{
Jianhua $\mathrm{Wu}^{1,2^{*}}$, Hui Qian ${ }^{1,2}$, Peiyue $\mathrm{Li}^{1,2}$, Yanxun Song ${ }^{3}$ \\ ${ }^{1}$ School of Environmental Science and Engineering, Chang'an University, No. 126 Yanta Road, Xi'an, 710054, Shaanxi, China. Emails: \\ wjh2005xy@126.com (Jianhua Wu), qianhui@chd.edu.cn (Hui Qian), lipy2@163.com (Peiyue Li). \\ ${ }^{2}$ Key Laboratory of Subsurface Hydrology and Ecology in Arid Areas, Ministry of Education, No. 126 Yanta Road, Xi'an, 710054, China. \\ ${ }^{3}$ College of Geology Engineering and Geomatics, Chang'an University, No. 126 Yanta Road, Xi'an, 710054, Shaanxi, China. Email: \\ songchden@163.com \\ *Corresponding author. Tel.: 86-29-82339327. Fax: 86-29-82339952. Email: wjh2005xy@126.com
}

\begin{abstract}
River runoff is not only a crucial part of the global water cycle, but it is also an important source for hydropower and an essential element of water balance. This study presents a system-theory-based model for river runoff forecasting taking the Hailiutu River as a case study. The forecasting model, designed for the Hailiutu watershed, was calibrated and verified by long-term precipitation observation data and groundwater exploitation data from the study area. Additionally, frequency analysis, taken as an optimization technique, was applied to improve prediction accuracy. Following model optimization, the overall relative prediction errors are below $10 \%$. The system-theory-based prediction model is applicable to river runoff forecasting, and following optimization by frequency analysis, the prediction error is acceptable.
\end{abstract}

Keywords: System theory; River runoff; Weight function; Frequency analysis; Uncertainty.

\section{INTRODUCTION}

Global climate change can impose great influence on the water cycle, especially with regard to precipitation and river runoff. River runoff, as an essential element of water balance, is an important part of the hydrological cycle. With the increasing awareness of the effects of climate change on nature and human beings, river runoff and its associated impact on the survival of human beings has received much attention from scholars around the world. Al-Taiee (2008) forecasted the Tigris River (Iraq) levels using a best relevant statistical model developed through time series analysis. Kliment et al. (2011) evaluated the trend of rainfall-runoff regimes in selected headwater areas using statistic testing and a Mann-Kendall seasonal test in the Czech Republic. In addition to climate change, human activities might also influence the hydrological regime. Jeníček (2009) assessed the impact of land cover changes on the hydrological regime using different methods. Shahraiyni et al. (2012) carried out a long-term simulation of daily streamflow in the Karoon River using a novel fuzzy modelling approach, the Active Learning Method, and proved its ability for runoff modelling by comparing it with a Genetic-Algorithm-optimized Support Vector Machine.

River runoff, directly influenced by precipitation and indirectly influenced by many other factors, is indispensable in maintaining the ecological and environmental health of a river basin. Its prediction has become a hot topic in recent years and many scholars have devoted themselves to the development of models for river runoff prediction and related forecasting practices. At present, models for river runoff prediction are mostly based on neural network theory (Atiya et al., 1999; Dibike and Solomatine, 2001; Hu et al., 2001; Kişi, 2007; Sahoo and Ray, 2006; Singh, et al., 2010; Yadav, et al., 2011; Wu et al., 2005). Additionally, some other methods have been introduced for river runoff prediction, for example, fuzzy model (Janál and Starý, 2009, 2012) and regression analysis (Wang, 2009). Sivakumar et al. (2001) performed monthly runoff prediction using phase space. Abrahart and See (2002) carried out a study on river flow forecasting using multi-model data fusion. Mahabir et al. (2003) studied seasonal runoff using fuzzy logic theory. Hang and Pan (2010) studied the daily flow prediction of the Taidong River with a genetic algorithm and least squares support vector machine (SVM). All these methods are proven applicable for river runoff prediction. However, these methods require considerable input data, which are sometimes difficult to collect, especially in remote arid areas where the long-term monitoring of runoff and precipitation is absent.

System theory was first proposed by Bertalanffy (1950) and it was intended to study the general pattern, system structures and rules of a system. Nowadays, the system theory has developed and has been widely adopted and used in various fields (An et al., 2005; Wang et al., 1999). Incorporated with fuzzy sets, Zhao et al. (2011) established a risk forecasting system and forecasted the construction engineering risk using system theory. The studied object, under the system theory, is treated as a system and then the correlations and variations among the system, elements, and environment structures and functions are analysed. Gray system theory, as an important branch of system theory, is powerful in dealing with unclear inner relationships, uncertain mechanisms, and insufficient information. Gray system theory was originally introduced by Deng (1982) and since, has been applied in various fields, such as hydrology (Trivedi and Singh, 2005) and energy engineering (Guo et al., 2011). Incorporated with other methods and theories, gray system theory has also been used in engineering design, information security, and time series prediction, etc. (Kayacan et al., 2011; Shen et al., 2009; Wang, 2011). Larsson et al. (2010) and Huang (2011) also highlighted the applicability of system theory for road safety and for the telecare of the elderly, respectively.

River runoff reflects the variations of its recharge and discharge, and in turn, the characteristics of river runoff variation depend on the input information of recharge and discharge. Furthermore, river runoff time series are stochastic with nu- 
merous uncertainties, and sometimes the information of the time series is insufficient. Therefore, the aims of the present study are 1) to establish a system-theory-based runoff prediction model by analyzing the relationships among river runoff, precipitation, and groundwater abstraction, and 2) to introduce an error reduction procedure based on frequency analysis to assist in time series analysis and prediction model optimization. Error reduction based on frequency analysis enables the model to be used in diverse conditions, even if the model calibration results are not perfect, and the model never relies solely on the model calibration. Numerous uncertainties are involved in dealing with stochastic time series. This study will provide an easy tool and a novel idea for the treatment of uncertain items.

\section{STUDY AREA}

\section{Location}

The Hailiutu River drainage area, a part of the Yellow River Watershed, is located in the north of Shaanxi Province, China. The Hailiutu River is a second-level tributary of the Yellow River. Fig. 1 shows the location and topography of the study area, which is high in the north and low in the south, and the Hailiutu River runs from northwest to southeast. It is $120.9 \mathrm{~km}$ in length (40 km within the study area) and intersects the Wuding River (runs from west to east) near Hanjiamiao Village.

Located in a semiarid area, the annual average temperature of the study area is $6.6-8.6^{\circ} \mathrm{C}$ and decreases from southeast to northwest. The lowest temperature is usually observed in January within the range of -9.9 to $11.3^{\circ} \mathrm{C}$ and is highest in July within the range $21.8-23.9^{\circ} \mathrm{C}$. The annual mean precipitation of the area is $334.0-364.74 \mathrm{~mm}$ and shows a decreasing trend from east to west. The precipitation is characterized by seasonal variation and its distribution is uneven both temporally and spatially. In summer and autumn, precipitation is abundant, whereas in winter and spring it is sparse. About $65 \%$ to $70 \%$ of the annual precipitation is observed during July, August and September. Precipitation also varies greatly inter-annually. The total annual precipitation in wet years can reach 654.5-695.4 $\mathrm{mm}$, whereas in dry years, it could be as low as 159.6-171.8 mm (Zhang, 2011).

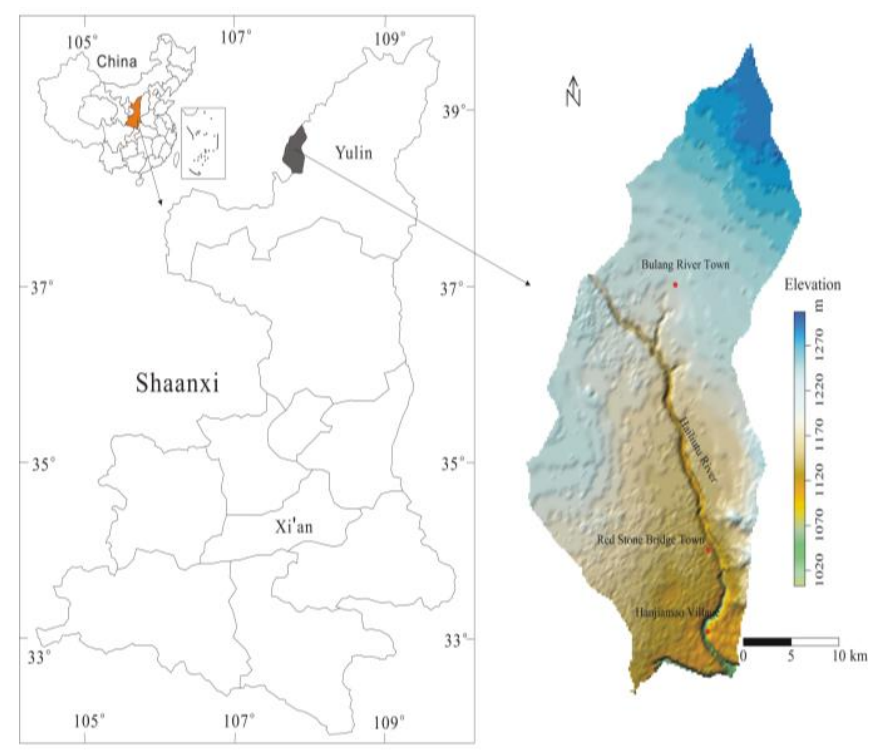

Fig. 1. Location and topography of the study area.

\section{Main factors influencing river runoff}

As an independent hydrogeological unit, Quaternary phreatic groundwater is recharged mainly from precipitation, and discharges predominantly as springs into the Hailiutu River, except for a very limited amount of artificial abstraction. If artificial water abstraction increases, groundwater discharge to the river will reduce, ultimately decreasing the river runoff. In addition, a small amount of surface water is also directly extracted from the Hailiutu River for domestic and agricultural uses, influencing the river runoff. Thus, precipitation and artificial water extraction are the two most important factors influencing the river runoff of the Hailiutu River.

\section{Precipitation}

As in many other areas in China, precipitation is one of the factors that affect river runoff. In the study area, the impact of precipitation on river runoff can be understood in two ways: (1) the precipitation can increase river runoff directly in the form of surface water flow, and (2) precipitation may infiltrate into the phreatic aquifer, elevating the groundwater level and subsequently, increasing the groundwater discharge to the river. The impact of the former is direct, and the river runoff will increase immediately following the rainfall event. This is evidenced by the diagrams of precipitation and river runoff (Fig. 2) in which the peak river runoff usually appears a very short time after the peak precipitation. However, the impact of the latter is indirect. There is a certain lag period before the infiltrated precipitation has an impact on the river runoff.

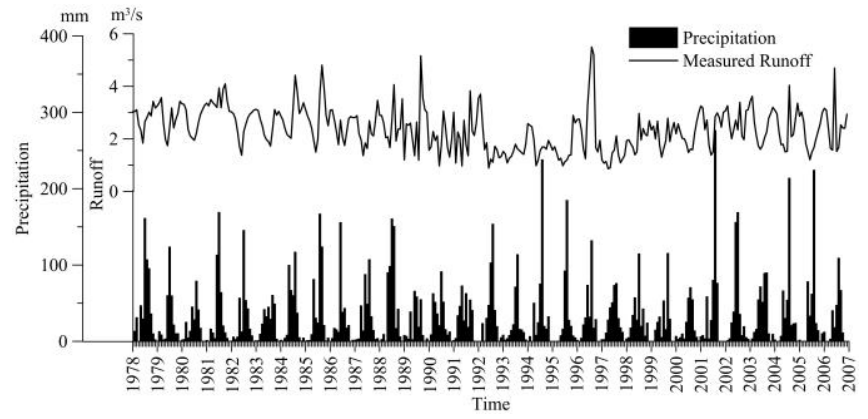

Fig. 2. Relationship between precipitation and runoff.

\section{Artificial extraction of groundwater resources}

In the study area, the artificial extraction of water is another factor that has an impact on the river runoff. Its influence on river runoff can also be classified into two aspects: (1) artificial extraction directly from the river, and (2) artificial abstraction of groundwater. The amount of artificial extraction directly from the river is small, but the lag period of its effects on river runoff is short. The latter has a longer lag period than the former. Groundwater extraction will lower the groundwater level, reducing the discharge of groundwater to the river.

Overall, precipitation can increase river runoff, whereas artificial extraction of surface water and groundwater will decrease it. Therefore, the correlation between river runoff and precipitation can be considered positive and that between river runoff and artificial water extraction considered negative. Based on the above assumption and analysis, the entire river can be taken as a system; the ratio of precipitation to artificial extraction is treated as an input, and the river runoff as an output. 


\section{FORECASTING MODEL BASED ON SYSTEM THEORY Model development}

A system can be constructed using the ratio of precipitation to artificial extraction as the input, the river runoff as the output, and the entire watershed as a black box. The three parts constitute a system that can be illustrated as follows (Wei, 2009):

$$
I(t) \rightarrow W(t) \rightarrow O(t)
$$

The black box system can be mathematically expressed as a mathematical convolution:

$Q(t)=\int_{-\infty}^{\infty} I(t-\tau) W(t, \tau) d \tau=I(t) \times W(t, \tau)$,

where $I(t)$ is the excitation function describing the input information, $W(t)$ is the characteristic function or weight function that depicts the physical characters of the system, and $Q(t)$ is the response function that describes the output information of the system.

Practically, precipitation is periodic resulting in the ratio of precipitation to artificial extraction being an impulse function varying with time. Accordingly, the input data are discontinuous. Generally, river runoff at a given time $t$, for a specific profile, is influenced by precipitation and artificial extraction during the period from $t$ to $t-n$, where $n$ is the furthest limit of input data. The furthest limit represents the maximum period within which precipitation can have an influence on runoff. Precipitation and artificial extraction occurring before $t-n$ or after $t$ will have no influence on the river runoff at given time $t$.

The input data are discontinuous. By discretization, the discretized runoff forecasting model can be established as follows (Wei, 2009):

$Q_{t}=\sum_{\tau=k}^{n} U_{t-\tau} W_{\tau}$

where $Q t$ is the river runoff of the $t^{\text {th }}$ month, $U_{\mathrm{t}-\tau}$ is the input item representing the ratio of precipitation to artificial extraction, $W_{\tau}$ is the coefficient of the linear functions and can be regarded as the weight of the model, and $k$ and $n$ are the nearest and furthest limits of the input data, respectively.

\section{Determination of model parameters}

The nearest limit $k$ and the furthest limit $n$ are two key parameters for the forecasting model. Parameter $k$ can be identified by the dynamic curves of the precipitation and river runoff, whereas the determination of the furthest limit $n$ is much more complex. According to the measured data from the Hailiutu River, the nearest limit $k$ was assigned a value of 0 . This means that the precipitation will influence the river runoff immediately without lag. In this study, $n$ is determined by iteration. To do this, (3) is rewritten in the following form (Song et al., 2011):

$Q_{t}=\sum_{\tau=0}^{k-1} U_{t-\tau} W_{\tau}+\sum_{\tau=k}^{n} U_{t-\tau} W_{\tau}+\sum_{\tau=n+1}^{t} U_{t-\tau} W_{\tau}$

It can be seen from Eq. (4) that the first item in the right-hand part of the equation represents the unaffected river runoff, which should have a constant value of 0 , and that the third item denotes the effect of precipitation before the $(n+1)^{\text {th }}$ month on the river runoff of the $t^{\text {th }}$ month. The third item should be approximately 0 if the value of $n$ is properly selected. The third item can be regarded as residual error of the system. Thus, when the absolute value of the third item is smallest, $n$ is optimally selected. In the present study, $n$ was initially assigned a value between 1 and 50 , and then the absolute values of the residual errors were calculated. If the absolute value of the residual error is smallest, $n$ is most appropriate. The process of calculation shows that when $n$ is 26 , the absolute value of the residual error $(0.182$ $\mathrm{m}^{3} / \mathrm{s}$ ) is the smallest; therefore, $n$ is assigned a value of 26 . This means that precipitation that occurred 26 months previously can still have an influence on river runoff.

Actually, $W_{\tau}$ is determined simultaneously with $n$. It can be calculated by the least squares method (Song et al., 2011). Namely:

$$
\begin{aligned}
& \varphi\left(W_{k}, W_{k+1}, \cdots, W_{n}\right)=\operatorname{Min}\left\{\sum_{t=1}^{N}\left(Q_{t}-Q_{t}{ }^{\prime}\right)^{2}\right\}, \\
& \frac{\partial \varphi}{\partial W_{\tau}}=0 \quad(\tau=k, k+1, k+2, \mathrm{~L} \mathrm{~L}, n),
\end{aligned}
$$

where $N$ is the number of measured data, $N \geq n \geq 0, Q_{t}$ is the forecasted runoff of the $t^{\text {th }}$ month, and $Q_{t}{ }^{\prime}$ is the measured runoff of the $t^{\text {th }}$ month. By solving Eq. (6), the weights can be obtained and then the river runoff can be calculated according to Eq. (3). The procedures for determining $n$ and $W_{\tau}$ are shown in Fig. 3.

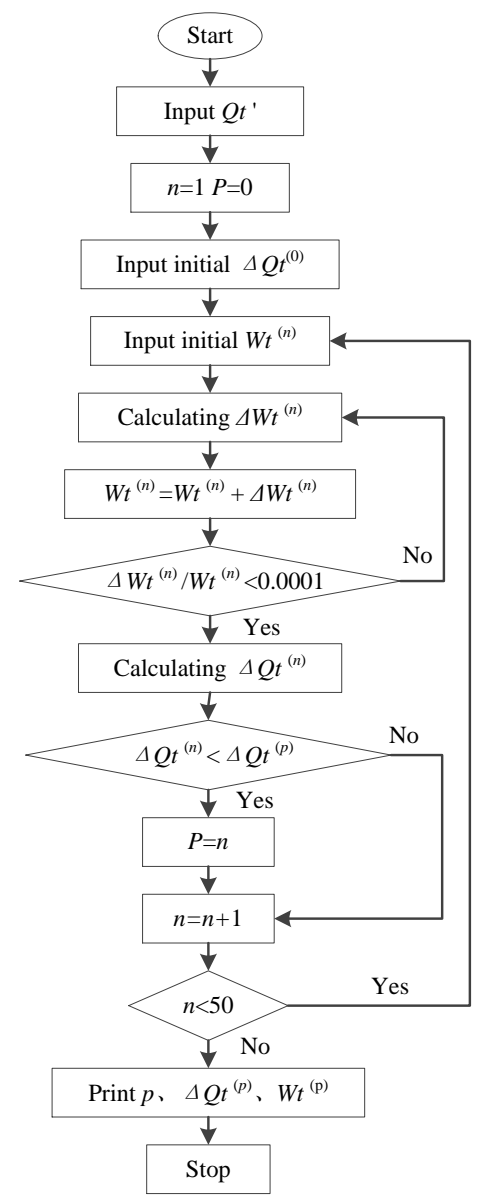

Fig. 3. Procedures for determining $n$ and $W_{\tau}$.

In Fig. 3, $Q_{t}^{\prime}$ is the observed river runoff at $t$ time, $W_{\tau(n)}$ is the weight function, $\Delta W^{(n)}$ denotes the iteration variable and 0.0001 is the predetermined iteration tolerance, $\Delta Q t^{(n)}$ denotes the re- 
sidual error of the system with the furthest limit being $n$ and the corresponding weight $W t^{(n)}$, and $\Delta Q^{(p)}$ is the smallest residual system error when the furthest limit is $p$ and weight is $W t^{(p)}$.

In the present study, the calculation processes were implemented with joint application of Matlab, Visual Basic programming and Microsoft Excel. The calculated $W_{j}$ is shown in Fig. 4, which shows the weights as an approximate unimodal distribution, which indicates that the output item is not sensitive to the groundwater discharge and the feedback is hysteretic.

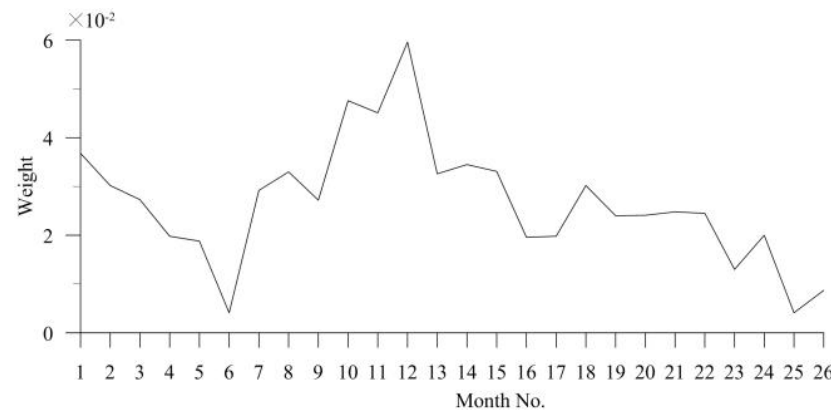

Fig. 4. Distribution of weight function.

\section{Model calibration}

The precipitation time series and river runoff time series are available from January 1978 to December 2006, but the artificial water extraction time series are only available from November 1983 to December 2006. In the study, the predicted runoff series are from November 1985 to December 2006. The time series of the precipitation and river runoff are longer than that of the artificial exploitation. In order to maintain consistency in the length of the time series, only the data from November 1985 to December 2006 were used in the model calibration and verification. The data from November 1985 to November 1999 were used for model calibration and those from December 1999 to December 2006 were used for model verification. The curves of the measured and forecasted runoff are shown in Fig. 5.

As shown in Fig. 5, the curves of the observed and forecasted data fit fairly well in the calibration period. The relative prediction errors of most periods are under $20 \%$, except for some extreme events that reflect the pulsing characteristics of the direct recharge to the river from precipitation. The relative prediction errors in the period 1992 to 1998 are somewhat larger than in other periods because of many uncertain factors during this period, such as manual interference to the land cover, reservoir control of the upstream and probable mistakes in runoff records. However, the variation trend of the predicted curve is generally consistent with the observed one. Simulation is a rather complex task which involves many uncertain factors. It is difficult and even impossible to make an exact prediction based on the available observed data. All we need to do and all we can do is to simulate the variation trend by defining the prediction error within an acceptable limit. It is the variation trend, not the extreme value itself, which is actually of importance to the decision makers. Despite the bigger prediction errors in some extreme values, the simulation can still be of use to decision makers if the trend of the predicted runoff is in accordance with that observed. Actually, it is rather difficult to obtain a perfect prediction by simple model calibration. Certain optimization techniques should be implemented to improve prediction accuracy, which will be introduced and discussed later in the section of model optimization.

\section{Model verification}

For verifying the general acceptability of the model for river runoff forecasting, runoffs from December 1999 to December 2006 were forecasted with the model. The forecasted and measured runoffs are presented in Fig. 6. It can be seen from Fig. 6 that the variation trend of the forecasted runoff is in good agreement with that of the measured runoff. In the verification period, the mean value of the measured runoff from December 1999 to December 2006 is $2.42 \mathrm{~m}^{3} / \mathrm{s}$ and the value of the forecasted runoff is $2.27 \mathrm{~m}^{3} / \mathrm{s}$. The mean prediction error is 0.15 $\mathrm{m}^{3} / \mathrm{d}$. The relative error between the observed and forecasted values was calculated as per the following formula:

$\delta=\frac{Q-Q^{\prime}}{Q^{\prime}} \times 100 \%$,

where $\delta$ denotes the relative prediction error, and $Q$ and $Q^{\prime}$ represent the forecasted and measured runoffs, respectively.

The relative prediction error is $6.20 \%$ during the period of model verification, which indicates that the forecasted results in the verification period are in good agreement with the measured data, and that the model with the calibrated parameters, is generally acceptable for river runoff forecasting. However, the model performance can be further optimized. In the present study, the model before optimization is called the original model, and the model after optimization is named the optimized model.

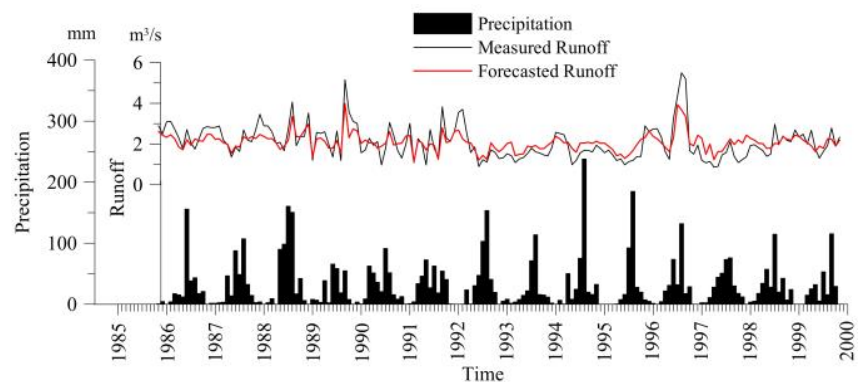

Fig. 5. Calibration of the model.

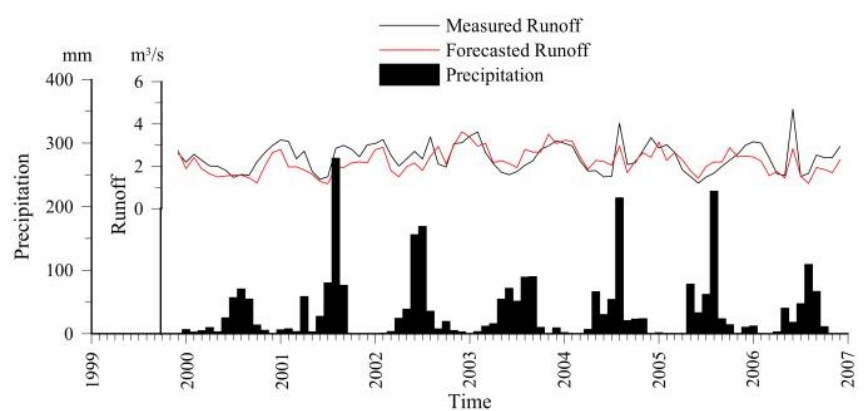

Fig. 6. Verification results of the model.

\section{Model optimization by frequency analysis}

During the calibration period, some extreme flow conditions are not forecasted well by the model, and during the verification period, although the forecasted results are much better, the relative errors for some points are still unsatisfactory. Theoretically, the prediction errors can be reduced further by introducing frequency analysis as a method for model optimization.

In hydrology, frequency is defined as the number of occurrences of an event or a phenomenon during a given period (Adrien, 2004). It is a statistical concept that denotes the probability of the occurrence of an event. To determine the frequency, 
the time series should be first arranged in descending order, and then it is calculated by the following formula (Wei and Wang, 2005):

$p=\frac{m}{N+1} \times 100 \%$,

where $m$ is the serial number of the arrangement, $N$ is the total number of samples, and $p$ is the frequency or the probability of occurrence. In the present study, this means the frequency of the monthly river runoff.

Positive correlation between the prediction errors and observed river runoff was observed and this is shown in Fig. 7. It can be seen from Fig. 7 that the prediction error shows a decreasing trend with the observed river runoff. Thus, when the frequency or probability of the observed runoff decreases, the prediction error reduces accordingly. The fitting equation is written in a general form as Eq. (9):

$Y=a+\frac{b}{X}$,

where $Y$ represents the prediction error, $X$ is the observed river runoff, and $a$ and $b$ are two constants. For the time series of April, $a$ is -94.36 and $b$ is 200.12 and the correlation coefficient for the time series of April is 0.9304 .

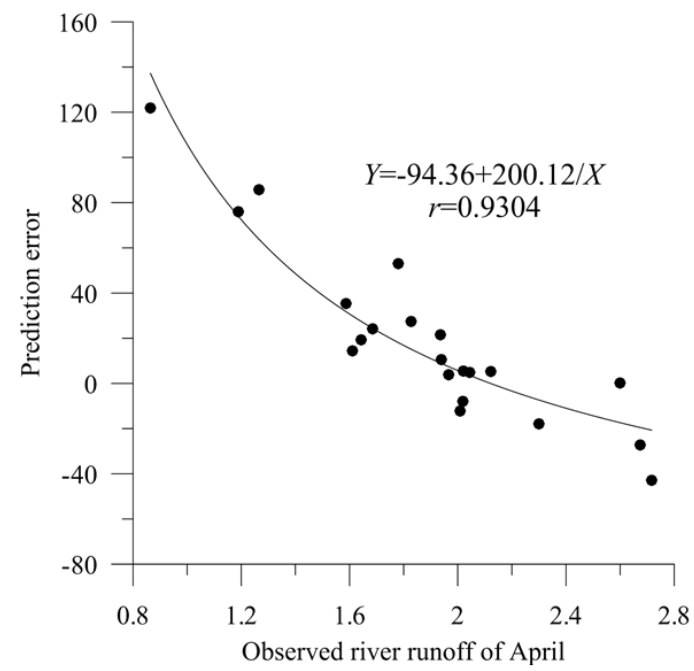

Fig. 7. Relation between prediction errors and the observed river runoff.

The relation of prediction error with observed runoff is helpful in model optimization. As indicated by Eq. (9), the prediction error can be corrected according to the magnitude of the error. However, forecasted values at different frequencies usually have different prediction errors. It is illogical to correct all forecasted runoffs with a single error. Therefore, frequency analysis was used to determine the prediction errors of predicted runoffs at different frequencies. Generally, four steps should be followed using frequency analysis for model optimization, and these procedures, taking the time series of April as an example, are summarized as follows:

\section{Step 1: River runoff prediction by original model}

To determine prediction error, the river runoff should be forecasted primarily by using the original model. Through model calibration and verification, the appropriate model parameters can be determined. Although prediction errors during these periods are within acceptable limits, the model can be further optimized by using frequency analysis to enhance the model performance.

\section{Step 2: Calculating the theoretical error}

The measured runoffs and those forecasted by the original model for April from 1986 to 2006 are arranged in a descending order. In hydrology, a Pearson type III distribution (P-III distribution, it is also known as a Weibull distribution) is commonly used for depicting the distribution of a time series. The P-III distributions of the two series are shown in Fig. 8. In this figure, $E_{x}$ denotes the mathematical expectation of the time series, $\mathrm{C}_{\mathrm{V}}$ is the coefficient of variation, and $\mathrm{C}_{\mathrm{S}}$ is the coefficient of skewness.

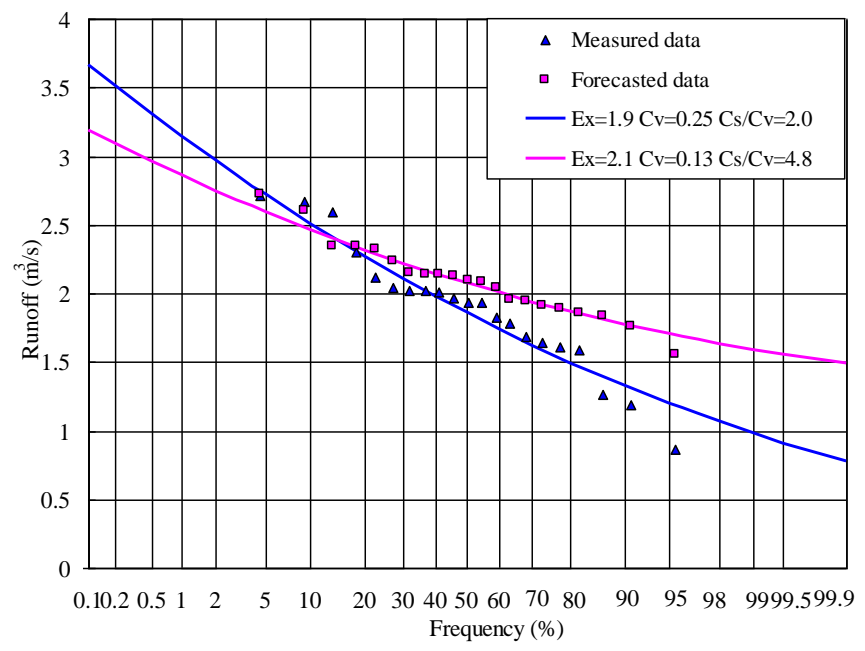

Fig. 8. P-III distributions of observed and forecasted river runoffs of April.

The prediction errors between the two curves are called the theoretical prediction errors. As shown in Fig. 8, the theoretical prediction errors have different values under different frequencies. A theoretical prediction error under a specific frequency can be read from the two curves. For instance, the theoretical prediction error is $26.67 \%$ under a frequency of $80 \%$.

\section{Step 3: Determining the error of the forecasted results}

As new data, the forecasted river runoff of a specific period is added into the time series of the measured runoff and then a new time series can be constructed. The frequency of the added data in the new time series can be calculated as per Eq. (8), after which the theoretical prediction error of the forecasted runoff under the calculated frequency can be determined by Fig. 8 . For example, the river runoff forecasted by the original model in April 2003 is $2.23 \mathrm{~m}^{3} / \mathrm{s}$. The forecasted runoff is added into the time series of the measured runoff, and the new time series is arranged in descending order. Then the frequency of the forecasted runoff can be calculated by Eq. (8), which is $27.27 \%$ in the present study. The theoretical prediction error under a frequency of $27.27 \%$ is approximately $3.85 \%$, as read from Fig. 8. Thus, this error is taken as the forecasted error of runoff in April 2003 and will be used for the error reduction in step 4. Only one runoff datum can be forecasted each time and therefore, one frequency can be determined each time. By loop computation, the frequencies of all forecasted data can be achieved. 


\section{Step 4: Error correction and model optimization}

The prediction error of the forecasted runoffs in April 2003 is substituted into Eq. (9) and then the optimized runoffs can be achieved. The optimized runoff in April 2003 is $2.06 \mathrm{~m}^{3} / \mathrm{s}$, which is very close to the observed runoff of the same period, and the prediction error after optimization is $-2.83 \%$ which is lower than that before optimization. The observed, forecasted and optimized runoffs of Aprils from 1986 to 2006 are shown in Table 1. The prediction errors before and after optimization are also listed in Table 1.

Table 1. Comparison of measured, forecasted and optimized results of April from 1986 to 2006.

\begin{tabular}{|c|c|c|c|c|c|c|}
\hline Year & Month & $\begin{array}{c}\text { Measured } \\
\text { runoff } \\
\left(\mathrm{m}^{3} / \mathrm{s}\right)\end{array}$ & $\begin{array}{c}\text { Forecasted } \\
\text { runoff } \\
\left(\mathrm{m}^{3} / \mathrm{s}\right)\end{array}$ & $\begin{array}{c}\text { Optimized } \\
\text { runoff } \\
\left(\mathrm{m}^{3} / \mathrm{s}\right)\end{array}$ & $\begin{array}{l}\text { Prediction } \\
\text { error before } \\
\text { optimization } \\
\quad(\%)\end{array}$ & $\begin{array}{c}\text { Prediction } \\
\text { error after } \\
\text { optimization } \\
\quad(\%)\end{array}$ \\
\hline 1986 & April & 2.3 & 1.89 & 2.1 & -17.86 & -12.61 \\
\hline 1987 & April & 1.97 & 2.4 & 2.00 & 3.84 & 1.52 \\
\hline 1988 & April & 2.4 & 2.14 & 2.6 & 4.86 & 0.98 \\
\hline 1989 & April & 2.6 & 2.6 & 2.53 & 0.09 & -2.69 \\
\hline 1990 & April & 1.94 & 2.15 & 2.6 & 10.57 & 6.19 \\
\hline 1991 & April & 2.2 & 2.13 & 2.6 & 5.47 & 1.98 \\
\hline 1992 & April & 1.59 & 2.15 & 1.76 & 35.26 & 10.69 \\
\hline 1993 & April & 1.27 & 2.35 & 1.58 & 85.62 & 24.41 \\
\hline 1994 & April & 1.94 & 2.35 & 2.9 & 21.43 & 7.73 \\
\hline 1995 & April & 1.19 & 2.9 & 1.23 & 75.99 & 3.36 \\
\hline 1996 & April & 1.61 & 1.84 & 1.83 & 14.48 & 13.66 \\
\hline 1997 & April & 0.86 & 1.92 & 0.92 & 121.85 & 6.98 \\
\hline 1998 & April & 1.69 & 2.9 & 2.3 & 24.9 & 20.12 \\
\hline 1999 & April & 2.67 & 1.94 & 2.35 & -27.30 & -11.99 \\
\hline 2000 & April & 2.2 & 1.86 & 1.86 & -7.92 & -7.92 \\
\hline 2001 & April & 2.72 & 1.55 & 2.38 & -42.82 & -12.50 \\
\hline 2002 & April & 2.1 & 1.76 & 1.80 & -12.22 & -10.45 \\
\hline 2003 & April & 2.12 & 2.23 & 2.6 & 5.28 & -2.83 \\
\hline 2004 & April & 1.78 & 2.72 & 1.96 & 52.98 & 10.11 \\
\hline 2005 & April & 1.83 & 2.33 & 2.9 & 27.47 & 14.21 \\
\hline 2006 & April & 1.64 & 1.96 & 1.89 & 19.17 & 15.24 \\
\hline
\end{tabular}

As can be seen from Table 1, the prediction accuracy of most Aprils has been improved, and the prediction errors after optimization by frequency analysis are lowered which reveals that the optimization by frequency analysis is helpful and applicable in prediction error reduction. By this method, the prediction accuracy of the model will no longer rely merely on model calibration. Thus, when the model calibration is not as satisfactory as we would wish, the model can still be used for prediction, which will reduce dramatically the time and energy consumed in the model calibration phase.

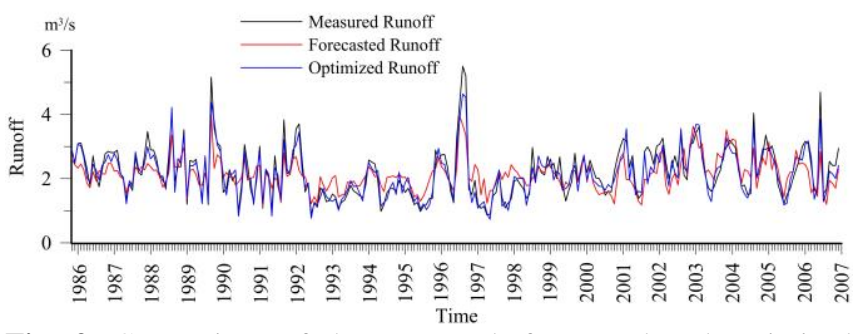

Fig. 9. Comparison of the measured, forecasted and optimized river runoffs.
In a similar way, the forecasted time series of other months can be optimized. The model optimization can be implemented with Visual Basic programming. The comparison among the optimized runoffs, measured runoffs and the forecasted runoffs using the original model from November 1985 to December 2006 is shown in Fig. 9.

Compared with the forecasted results before optimization, the prediction accuracy of the entire time series has been improved following model optimization by frequency analysis. The prediction of the extreme flow is also improved, although some error still exists. The mean observed and optimized runoffs in each month are listed in Table 2. As shown in Table 2, the overall prediction error of each month is within the range of $-13.615 \%$ to $6.071 \%$ which is acceptable in hydrological prediction. The comparison also indicates that the system-based model, incorporating frequency analysis, is a useful tool for hydrologists and decision makers to study and manage river water resources in the study area.

Table 2. Comparison of observed and optimized runoffs of each month.

\begin{tabular}{lccc}
\hline Month & $\begin{array}{c}\text { Observed } \\
\text { runoff }\left(\mathrm{m}^{3} / \mathrm{s}\right)\end{array}$ & $\begin{array}{c}\text { Optimized } \\
\text { runoff }\left(\mathrm{m}^{3} / \mathrm{s}\right)\end{array}$ & $\begin{array}{c}\text { Prediction error after } \\
\text { optimization }(\%)\end{array}$ \\
\hline January & 2.74 & 2.75 & -8.124 \\
February & 2.11 & 2.54 & -13.615 \\
March & 2.78 & 2.1095 & -5.134 \\
April & 1.51 & 1.23 & 4.399 \\
May & 1.75 & 1.14 & 6.071 \\
June & 1.44 & 1.58 & 2.740 \\
July & 1.86 & 1.51 & 0.848 \\
August & 2.00 & 2.46 & -4.781 \\
September & 2.12 & 2.85 & -10.489 \\
October & 2.1103 & 2.1785 & 3.131 \\
November & 2.76 & 2.37 & 1.534 \\
December & 2.07 & 2.41 & -4.240 \\
\hline
\end{tabular}

\section{CONCLUSIONS}

A system-theory-based model for river runoff forecasting was established in the study and the frequency analysis method was used to optimize the model to reduce prediction errors. The calibration and verification shows that the forecasted results of the monthly river runoff are generally in good agreement with the observed data. Some bigger prediction errors can be observed in some of the extreme flows, which reflect the pulsing characteristics of the direct recharge to the river from precipitation. The model was optimized by frequency analysis to reduce the prediction error. The prediction accuracy was improved significantly following optimization and the prediction error of mean monthly runoff following optimization is usually below $10 \%$. The system-based model, incorporating frequency analysis, is feasible and applicable to river runoff prediction and it provides an effective tool for river water management.

Acknowledgement. This study was supported by the Doctor Postgraduate Technical Project of Chang'an University (2013G5290002 and CHD2011ZY022), the special Fund for Basic Scientific Research of Central Colleges, Chang'an University (CHD2011ZY020 and CHD2012TD003) and the National Natural Science Foundation of China (41172212). The editor and anonymous reviewers are sincerely acknowledged for their useful comments. 


\section{REFERENCES}

Abrahart, R.J., See, L., 2002. Multi-model data fusion for river flow forecasting: an evaluation of six alternative methods based on two contrasting catchments. Hydrol. Earth Syst. Sc. $6,4,655-670$.

Adrien, N.G., 2004. Computational Hydraulics and Hydrology: An Illustrated Dictionary. CRC Press, New York.

Al-Taiee, T.M., 2008. Statistical prediction of Tigris River levels at Mosul hydrological station, north IRAQ. J. Hydrol. Hydromech., 56, 4, 272-279.

An, Y.H., Tang, G.Y., Zhang, F.C., Yao, X.J., 2005. Application of systematic theory and frequency analytic approach on water resource evaluation. Site Investigation Science and Technology, 5, 38-40 (in Chinese.)

Atiya, A.F., El-Shoura, S.M., Shaheen, S.I., El-Sherif, M.S., 1999. A Comparison Between Neural-Network Forecasting Techniques-Case Study: River Flow Forecasting. IEEE Transactions on Neural Networks, 10, 2, 402-409.

Bertalanffy, L.V., 1950. An outline of general system theory. Brit. J. Philos. Sci., 1, 2, 134-165.

Deng, J.L., 1982. Control problems of grey systems. Systems and Control Letters, 5, 288-294.

Dibike, Y.B., Solomatine, D.P., 2001. River Flow Forecasting Using Artificial Neural Networks. Physics and Chemistry of the Earth, Part B: Hydrology, Oceans and Atmosphere, 26, $1,1-7$.

Guo, J.J., Wu, J.Y., Wang, R.Z., 2011. A new approach to energy consumption prediction of domestic heat pump water heater based on grey system theory. Energ. Buildings, 43, 1273-1279.

Hang, Q.F., Pan, D.H., 2010. Daily flow prediction of Taidong River based on genetic algorithm and the least square support vector machine (SVM). Pearl River, 4, 6-7, 21. (in Chinese.)

Hu, T.S., Lam, K.C., Ng, S.T., 2001. River flow time series prediction with a range-dependent neural network. Hydrological Sciences-Journal-des Sciences Hydrologiques, 46, 5, 729-145.

Huang, J.C., 2011. Application of grey system theory in telecare. Computers in Biology and Medicine, 41, 302-306.

Janál, P., Starý, M., 2009. Fuzzy model use for prediction of the state of emergency of river basin in the case of flash flood. J. Hydrol. Hydromech., 57, 3, 145-153.

Janál, P., Starý, M., 2012. Fuzzy model use for prediction of the state of emergency of river basin in the case of flash floodPart 2. J. Hydrol. Hydromech., 60, 3, 162-173.

Jeníček, M., 2009. Runoff changes in areas differing in landuse in the Blanice river basin-application of the deterministic model. J. Hydrol. Hydromech., 57, 3, 154-161.

Kayacan, E., Ulutas, B., Kaynak, O., 2011. Grey system theorybased models in time series prediction. Expert Systems with Applications, 37, 1784-1789.

Kişi, Ö., 2007. Streamflow Forecasting Using Different Artificial Neural Network Algorithms. J. Hydrol. Eng., 12, 5, 532-539.

Kliment, Z., Matoušková, M., Ledvinka, O., Královec, V., 2011. Trend analysis of rainfall-runoff regimes in selected headwater areas of the Czech Republic. J. Hydrol. Hydromech., 59, 1, 36-50.

Larsson, P., Dekker, S.W.A., Tingvall, C., 2010. The need for a systems theory approach to road safety. Safety Sci., 48, 1167-1174.
Mahabir, C., Hicks, F.E., Fayek, A.R., 2003. Application of fuzzy logic to forecast seasonal runoff. Hydrol. Process., 17, 3749-3762.

Sahoo, G.B., Ray, C., 2006. Flow forecasting for a Hawaii stream using rating curves and neural networks. J. Hydrol., 317, 63-80.

Shahraiyni, H.T., Ghafouri, M.R., Shouraki, S.B., Saghafian, B., Nasseri, M., 2012. Comparison between active learning method and support vector machine for runoff modeling. J. Hydrol. Hydromech., 60, 1, 16-32.

Shen, V.R.L., Chung, Y.F., Chen, T.S., 2009. A novel application of grey system theory to information security (Part I). Computer Standards \& Interfaces, 31, 277-281.

Singh, P., Kumar, A., Kumar, N., Kishore, N., 2010. Hydrometeorological correlations and relationships for estimating streamflow for Gangotri Glacier basin in Western Himalayas. International Journal of Water Resources and Environmental Engineering, 2, 3, 60-69.

Sivakumar, B., Berndtsson, R., Persson, M., 2001. Monthly runoff prediction using phase space reconstruction. Hydrological Sciences-Journal-des Sciences Hydrologiques, 46, 3, 377-387.

Song, Y.X., Wu, J.H., Li, P.Y., 2011. Application of System Theory in the Calculation of Groundwater Resources Availability in Balasu Water Source. Proceedings of 2011 IEEE 3rd International Conference on Communication Software and Networks, ICCSN 2011. Xi' an, China, May, 27-29, pp. 707-710.

Trivedi, H.V., Singh, J.K., 2005. Application of Grey System Theory in the Development of a Runoff Prediction Model. Biosystems Engineering, 92, 4, 521-526.

Wang, H.X., Yan, T.Z., Tang, H.M., Teng, W.F., 1999. Forecasting and decision-making of systematic theories for engineering geology in environmental geosciences. Journal of China University of Geosciences, 10, 4, 327-328.

Wang, W.D., 2009. Mid-long term average flow forecast of Jiyuan Hydrological Station of Python River. Henan Water Resources \& South-to-North Water Diversion, 10, 35-39. (in Chinese.)

Wang, K.C., 2011. A hybrid Kansei engineering design expert system based on grey system theory and support vector regression. Expert Systems with Applications, 38, 8738-8750.

Wei, H.S., 2009. System theory. World Book Publishing Company, Beijing. (in Chinese.)

Wei, Y.X., Wang, L.X., 2005. Engineering hydrology. China Water Conservancy and Hydropower Press, Beijing. (in Chinese.)

Wu, J.S., Han, J., Annambhotla, S., Bryant, S., 2005. Artificial Neural Networks for Forecasting Watershed Runoff and Stream Flows. J. Hydrol. Eng., 10, 3, 216-222.

Yadav, D., Naresh, R., Sharma, V., 2011. Stream flow forecasting using Levenberg-Marquardt algorithm approach. International Journal of Water Resources and Environmental Engineering, 3, 1, aa30-40.

Zhao, Y.J., Liu, X.J., Zhao, Y., 2011. Forecast for construction engineering risk based on fuzzy sets and systems theory. Systems Engineering Procedia, 1, 156-161.

Zhang, Q., 2011. Research on the vegetation change and the environmental impact factors in Hailiutu River Basin. Dissertation. China University of Geosciences (Beijing), Beijing. (in Chinese.) 